\section{Late paraphrenia revisited}

\author{
ROBERT HOWARD and PETER RABINS
}

There are no specific diagnostic codings within ICD-10 or DSM-IV for patients who develop a non-organic and non-affective psychosis with onset in late life. This would be fine if a satisfactory alternative diagnosis had been included for the psychoses formerly known as late paraphrenia and late-onset schizophrenia. Dissatisfaction with these diagnoses prior to the publication of ICD10 and DSM-IV reflected long-standing uncertainty about their relationship with schizophrenia, delusional disorders, organic and atypical affective psychoses. While such uncertainty has not been dispelled, classification of the majority of these patients within paranoid schizophrenia may not be valid, ignores apparent specific risk factors associated with the condition, presumes a course and treatment response that is not substantiated by data, and by removing all coding for late age at onset will make such patients difficult to identify for future study. Revisions of ICD and DSM should attempt to address these issues and we suggest reintroduction of coding for late age at onset.

\section{HISTORICAL BACKGROUND}

Study of late-onset schizophrenia began with Manfred Bleuler (1943) who examined symptomatology and outcome in 126 patients with illness onset after the age of 40 years and concluded that such cases had much in common with those that had a more typical early onset. Roth \& Morrisey (1952) resurrected Kraepelin's term for a psychosis characterised by hallucinations and delusions without deterioration or disturbance of affective response. They chose the term "late paraphrenia" to describe these patients who they believed had schizophrenia but with an onset delayed until after the age of 55 or 60 . Late paraphrenia was never meant to be anything more than a descriptive term, to distinguish the illness from chronic schizophrenia seen in mental institutions at that time and to emphasise clinical similarities with the condition described by Kraepelin. Syndromic coherence was suggested by widely replicated risk factors; female preponderance (Kay \& Roth, 1961; Herbert \& Jacobson, 1967; Howard et al, 1994), abnormal premorbid personality and social isolation (Kay \& Roth, 1961; Post, 1966; Kay et al, 1976), and deafness (Kay \& Roth, 1961; Herbert \& Jacobson, 1967; Cooper et al, 1974; Cooper, 1976; Cooper \& Curry, 1976), the term was readily adopted by European old age psychiatrists and was included in ICD-9 (World Health Organization, 1978). In the United States, inclusion within DSM-III-R (American Psychiatric Association, 1987) of a separate category of late-onset schizophrenia for cases with onset after age 44 seems largely to have been a reaction to the unsatisfactory and arbitrary upper age limit for onset that had hitherto prevailed for a diagnosis of schizophrenia (Rabins et al, 1984). Clinical similarities between cases of late-onset and early-onset schizophrenia so defined were considered to be more striking than any differences by influential North American workers (Pearlson et al, 1989). European psychiatrists have argued that differences in phenomenology (Howard et al, 1993) and aetiological factors (Castle \& Howard, 1992; Howard et al, 1997) may indicate a distinct or a group of distinct lateonset disorders.

\section{CURRENT DIAGNOSTIC OPTIONS WITHIN ICD-10}

Around $65 \%$ of patients with late-onset non-affective non-organic psychoses encountered by old-age psychiatrists will satisfy ICD-10 criteria for the diagnosis of paranoid schizophrenia (F20.0) (Quintal et al, 1991; Howard et al, 1994). Within the guidelines accompanying ICD-10, we are told that this diagnosis includes paraphrenic schizophrenia and applies to cases characterised by prominent hallucinations and delusions, and in whom disturbances of affect, volition and speech and catatonic symptoms are inconspicuous. Almost all cases that do not meet the criteria for paranoid schizophrenia are accommodated within persistent delusional disorders (F22), and the guidelines suggest that delusional disorder (F22.0) "includes paraphrenia (late)". Distinction between cases of the illness previously known as late paraphrenia, which should now be labelled paranoid schizophrenia or delusional disorder, is heavily dependent upon the presence or absence of clear and persistent auditory hallucinations. Somewhat confusingly, this distinction is blurred by the guidelines for delusional disorder which state that "occasional or transitory auditory hallucinations, particularly in elderly patients, do not rule out this diagnosis provided they are not typically schizophrenic and form only a small part of the overall clinical picture". The diagnostic category "other persistent delusional disorders" (F22.8) is intended to include what are termed "involutional paranoid states" and represents a catch-all for illnesses in which delusions are accompanied by persistent hallucinatory voices or by schizophrenic symptoms considered insufficient to meet criteria for schizophrenia. The absence of formal thought disorder and relative lack of negative symptoms are not addressed.

For those psychoses in which the syndrome can be attributable to an independently diagnosable cerebral or systemic disease, the ICD-10 diagnosis of organic delusional (schizophrenia-like) disorder (F06.2) is appropriate. The guidelines advise that the diagnosis should not be made if the presumed evidence of organic causation is non-specific or limited to findings such as large ventricles or soft neurological signs.

\section{DIAGNOSIS WITHIN DSM - IV}

There is no late-onset category for schizophrenia within DSM-IV, but consideration is given to cases that may begin late in life (after the age of 45). Such cases are said to be essentially similar to earlier-onset cases except for a higher ratio of women together with better occupational and marital histories. The clinical presentation is said to be more likely to include paranoid delusions and hallucinations and is less likely to include disorganised and negative symptoms. Specific mention is made of those cases with the "oldest age at onset" (over 
60 ), in whom sensory deficits are acknowledged to be more common than in the elderly general population. Most cases previously coded under late-onset schizophrenia in DSM-III-R are now accommodated within "schizophrenia paranoid type" (295.30). Patients recognisable as cases of late paraphrenia will also find a home within the alternative diagnosis of delusional disorder (297.1). An onset in middle or late life is specifically mentioned in the diagnostic guidelines, together with a note that tactile and olfactory hallucinations related to the delusional theme may be present. As for ICD-10, auditory and visual hallucinations may be present, but should not be prominent, for the diagnosis to be made.

\section{DO ICD - IO AND DSM - IV MEET THE NEEDS OF OLD AGE PSYCHIATRISTS?}

Most practising old age psychiatrists will be familiar with a group of patients who present to their services with onset of a non-affective non-organic psychosis after the age of 60 and who, in terms of phenomenology and associated factors, essentially have late paraphrenia as described by Kay \& Roth (1961). The clinical impression of such workers remains that these patients have more in common with others with late paraphrenia than they have with younger-onset subjects with schizophrenia, but that the richness of core schizophrenic symptomatology and hallucinatory experiences suffered by this group does not justify their inclusion within delusional disorder. In the absence, therefore, of an acceptable diagnostic category within ICD-10, most European old age psychiatrists have continued to use the diagnosis late paraphrenia but have been unable to code this appropriately.

\section{WHAT WILL BE THE EFFECT OF ICD - IO AND DSM - IV FOR RESEARCHERS}

For those of us who study late-life psychoses, the removal of late age-at-onset coding has caused concern partly because, compared with younger-onset schizophrenia, so little attention has ever been focused on these patients, but more importantly because it will in future be very difficult to identify cases for research studies (Quintal et al, 1991).

ROBERT HOWARD, MD. Institute of Psychiatry, London SE5 8AF; PETER RABINS, MD. Johns Hopkins Hospital, Baltimore, MD 21287-7279, USA

Correspondence: Dr R. Howard, Institute of Psychiatry, London SE5 8AF. Fax: 0 171 701 0167; e-mail: rhoward@iop.bpmf.ac.uk

(First received 25 March 1997, final revision 17 June 1997, accepted 30 June 1997)

\section{A FUTURE FOR LATE-ONSET SCHIZOPHRENIA-LIKE DISORDERS}

While the return of the term late paraphrenia would no doubt prove popular with some, it would also be controversial and would prolong the ambiguity surrounding these disorders and their relationship with schizophrenia. The suggestion that late ageat-onset should be coded is less controversial and would go some way towards stimulating future study of these disorders. Indeed, research into late-onset schizophrenia-like illnesses may offer clues concerning the aetiology of early adult life onset schizophrenia (Rabins, 1995). The question remains how to label and code for these disorders in a simple and practical way that reflects our limited understanding of the nosological status of these patients but which will prove sufficiently useful for clinicians so that they are happy to abandon late paraphrenia. A further question remains; at what age should onset of schizophrenia be considered to be late? We would propose that the term late-onset schizophrenia be re-introduced to describe patients who fulfil diagnostic criteria for schizophrenia but have an illness onset after the age of 44 years. The choice of 44 years is an arbitrary one, but would at least be consistent with previous definitions of lateonset for schizophrenia. The incidence of schizophrenia, after declining from a peak in early adult life, rises again in the seventh and eighth decades, particularly in women (Castle \& Murray, 1994; Van Os et al, 1995), which (together with some of the evidence reviewed above) does suggest that a different set of aetiological factors have come into play in this extreme late-onset group. Thus, while cases of schizophrenia with a first onset after the age of 44 (but before 60) years probably really do represent delayed expression of more usual, early adult life onset illness, those which begin after the age of 60 years are more likely to be phenocopies of 'true' schizophrenia, whose aetiology owes much to neurodegenerative factors such as sensory and subtle cognitive deficits.
We believe that there is a good case for a further codeable category for cases with onset after the age of 60 years which should be termed late life onset schizophrenia-like psychoses. Separate codes for onset between 45 and 59, and after 60 years should be provided. Since currently the fifth coding digit in DSM-IV is unused, this could easily be used to code for age at onset. For example, a case of paranoid schizophrenia with illness onset at age 30 years would be coded 295.30, with onset at 50 years (lateonset schizophrenia) 295.31 , and at 70 years (late life onset schizophrenia-like psychosis) 295.32. Although beyond the remit of this editorial, there is also a strong case for an age at onset code to be made available for affective disorders, since these illnesses span the whole of life, are aetiologically heterogeneous and onset age appears to contribute to such heterogeneity.

\section{REFERENCES}

American Psychiatric Association (1987) Diognostic and Statistical Manual of Mental Disorders (3rd edn) (DSM- III). Washington, DC: APA.

Blouler, M. (1943) Die spatschizophrenen krankheitsbilder. Fortschritte der Neurologie Psychiatrie. 15. 259-290.

Castle, D. J. Howard, R. (1992) What do we know about the aetiology of late-onset schizophrenia? European Psychiatry. 7. $99-108$.

- Murray, R. M. (1993) The epidemiology of late-onset schizophrenia. Schizophrenio Bulletin, 19.691-700.

Cooper, A. F. (1976) Deafness and psychiatric illness. British Journal of Psychiatry. 129. 216-226.

- Curry, A. R. (1976) The pathology of deafness in the paranoid and affective psychoses of later life. Journal of Psychosomatic Research, 20. 107-114.

_, _ , Kay, D. W. K., et al (1974) Hearing loss in paranoid and affective psychoses in the elderly. Loncet, ii, $851-854$.

Herbert, M. E. \& Jacobson, S. (1967) Late paraphrenia. British journal of Psychiatry. 113, 461-467.

Howard, R., Castle, D., Wessely, S., et ol (1993) A comparative study of 470 cases of early and late-onset schizophrenia. British journal of Psychiatry. 163. 352-357.

—. Almeida, O. \& Levy, R. (1994) Phenomenology. demography and diagnosis in late paraphrenia. Psychological Medicine, 24. 397-410.

_. Graham, C., Sham, P., et ol (1997) A controlled family study of late-onset non-affective psychosis (late paraphrenia). British journal of Psychiatry, 170, $511-514$. 
Km, D. W. K. Roth, M. (1961) Environmental and hereditary factors in the schizophrenias of old age ("late paraphrenia") and their bearing on the general problem of causation in schizophrenia. Journol of Mentol Science, 107. 649-686.

-, Cooper, A. F., Garaids, R. F., of of (1976) The differentiation of paranoid from affective psychoses by patients' premorbid personalities. British journol of Psychiatry. 129, 207-215

Paartson, G., Krezer, L., Rabins, P., ef of (19e8) A chart review study of late-onset and early-onset schizophrenia. Americon journal of Psychiotry, 146, 1568-1574.
Post, F. (1966) Persistent Persecutory Stotes. Oxford: Pergamon.

Quintal, M., Day-Cody, D. \& Lovy, R. (1991) Late paraphrenia and KCD-10. Internotional journal of Geriatric Psychiotry, 6. III-116.

Rabins, P.V. (1995) Can schizophrenia-like disorders beginning in late life tell us anything about early life onset schizophrenia? Journal of Mentol Health, 4. 177-181.

_, Pauber, S. \& Thomas, J. (1984) Can schizophrenia begin after age 44? Comprehensive Psychiatry, 25, 290-293.
Roth, M. \& Morrisey, J. D. (1952) Problems in the diagnosis and classification of mental disorders in old age. Journal of Mental Sciences, 98, 66-80.

Van Os, J., Howard, R., Takel, N., et of (1995) Increasing age is a risk factor for psychosis in the elderly. Social Psychiotry and Psychiotric Epidemiology, 30, 161-164.

World Health Organization (1970) Mentol Disorders: Glossory and Guide to their Classification in Accordance with The Ninth Revision of the International Clossification of Diseases and Reloted Health Problems (ICD-9). Geneva: WHO. 